\title{
СРАВНИТЕЛЬНЫЙ АНАЛИЗ МИРОВОГО ОПЫТА СОЗДАНИЯ И РАЗВИТИЯ ТЕРРИТОРИИ С ОСОБЫМ ПРАВОВЫМ СТАТУСОМ (НА ПРИМЕРЕ РАЗВИВАЮЩИХСЯ СТРАН АЗИИ) ${ }^{1}$
}

\section{COMPARATIVE ANALYSIS \\ OF THE WORLD EXPERIENCE IN CREATING AND DEVELOPING TERRITORIES WITH A SPECIAL LEGAL STATUS (FOR EXAMPLE, DEVELOPING COUNTRIES IN ASIA)}

P. Stroev

S. Makar

A. Dudnik

Summary: The article provides a comprehensive comparative analysis of the international practice of creating territories with a special legal status on the example of the functioning of special economic zones, comprehensively examines and systematizes conceptual approaches to the development of special economic zones in various regions of the world, highlights the main trends and prospects. The study found that in the Asian region, the current trend is the introduction of a new generation of global free trade zones, which are aimed at testing institutional innovations in solving specific problems of socio-economic development before they are implemented at the state or regional level. Instead of traditional tax incentives, Central government support in these zones is aimed at liberalizing the economy, including experimental investment policies. While many advanced economies use SEZs to encourage industrial modernization, emerging economies focus on special economic zones that focus on technology development. Special attention is paid to the classification of countries in the world according to the level of economic development that have territories with a special legal status on their territory.

Keywords: regional economy, territory with a special legal status, special economic zone, free trade zone, industry, spatial regulation, world experience.
Строев Павел Викторович

к.э.н., дочент, Финансовый университет при Правительстве Российской Федерации (г. Москва)

stroevpavel@gmail.com

Макар Светлана Владимировна

д.э.н., дочент, в.н.С., Финансовый университет при Правительстве Российской Федерачии (г. Москва) swetwn@mail.ru

Дудник Анна Игоревна

Лаборант-исследователь, Финансовый университет при Правительстве Российской Федерации (2. Москва) AIDudnik@fa.ru

Аннотация: В статье проведен комплексный сравнительный анализ международной практики создания территорий с особым правовым статусом на примере функционирования особых экономических зон, всесторонне рассмотрены и систематизированы концептуальные подходы к развитию специальных экономических зон в различных регионах мира, выделены основные тенденции и перспективы. В ходе исследования установлено, что в странах Азиатского региона современным трендом является внедрение глобальных зон свободной торговли нового поколения, которые нацелены на тестирование институциональных нововведений в решении конкретных проблем социально-экономического развития, прежде чем они будут внедрены на государственном или региональном уровне. Вместо традиционных налоговых стимулов поддержка со стороны центрального правительства в этих зонах направлена на либерализацию экономики, включая экспериментальную политику в области инвестиций. В то время как, многие страны с развитой экономикой используют $0 Э 3$ для стимулирования модернизации промышленности, в странах с развивающейся экономикой делают акцент на специальных экономические зоны, ориентированные на развитие технологий. Особое внимание уделяется классификации стран мира в соответствии с уровнем развития экономики, имеющие на своей территории с особым правовым статусом.

Ключевые слова: региональная экономика, территория с особым правовым статусом, особая экономическая зона, зона свободной торговли, промышленность, пространственное регулирование, мировой опыт.
$\mathrm{T}$ ерритории с особым правовым статусом - важнейший инструмент развития экономики в современном мире. Существует множество форм территорий с особым правовым статусом (далее - ТсОПС), различных направлений и масштабов деятельности. Их объединяют такие черты как ограниченная территория, особый режим для ведения бизнеса, налоговые и таможенные льготы. В ответ на такие меры государство ожидает приток прямых иностранных инвестиций, увеличение показателей экспорта, создание прямых и сопутствующих рабочих мест, стимулирование роста экономики не только в пределах ТсОПС, но и за ее границами. Однако опыт деятельности ТсОПС нельзя считать однородным, прежде всего, он зависит от целей создания этих зон и региона

1 Статья подготовлена по результатам исследований, выполненных за счет бюджетных средств по государственному заданию Финуниверситета 
их функционирования.

Мировая практика создания экономических зон с особым статусом достаточно обширна, это самый распространенный инструмент стимулирования развития территорий. На сегодняшний день существует два основных подхода к процедуре создания экономических зон метод «сверху-вниз» и «снизу-вверх» [1]. Первый метод предусматривает зоны, которые создаются по предложению и за счет государства (опыт Тайваня, Республики Кореи, Индии), либо инициативой государственных корпораций (опыт Великобритании, стран Латинской Америки, Юга и Востока Азии). Второй метод рассматривает зоны прочих форм собственности, в рамках которого принимается исключительно заявительная процедура организации особой экономической зоны (опыт Канады, Западной Европы, США), или необходимо принятие технико-экономического обоснования со стороны госорганов (опыт Турции и Аргентины) [2]. Среди территорий с особым правовым статусом имеется богатый опыт создания особых зон в Северной Америке и Азии [3].

Среди значительного количества видов территорий с особым правовым статусом наибольшее распространение получили особые экономические зоны (далее-ОЭЗ), став универсальным инструментом развития в мировой практике. ОЭЗ - географически разграниченные зоны, с помощью которых правительства различных стран стимулируют промышленную деятельность посредством налоговых и нормативных льгот, а также поддержки инфраструктуры. ОЭЗ широко используются в большинстве развивающихся и многих развитых странах.

ОЭЗ имеют много наименований и бывают разных видов и масштабов. Общим для них является то, что в пределах определенного периметра они обеспечивают регулятивный режим для предприятий и инвесторов, отличный от того, который применяется в национальной или субнациональной экономике страны в целом. Наиболее распространенными типами ОЭЗ являются вариации свободных зон, которые по сути являются отдельными таможенными территориями. Свободные экономические зоны получили широкое распространение в мире после подписания Киотской конвенции в 1973 г., согласной которой свободная зона представляет собой внешнеторговый анклав, где товары считаются находящимися за пределами таможенной территории [4]. В дополнение к освобождению от таможенных пошлин и тарифов, большинство зон также предлагают налоговые льготы, упрощенные правила в отношении доступа к земле и привлечения трудовых ресурсов, получению разрешений и лицензий, а также административное содействие. Поддержка инфраструктуры - это еще одна важная отличительная черта ОЭЗ, особенно в развивающихся странах, где базовая инфраструктура для бизнеса за пределами этих зон может быть плохо развита или совсем не развита. В обмен на эти таможенные, налоговые и административные льготы, меры поддержки бизнеса, инвестиции в инфраструктуру правительства ожидают, что инвесторы, работающие в ОЭЗ, создадут новые рабочие места, расширят экспорт, диверсифицируют экономику и увеличат производственные мощности.

ОЭЗ используются более, чем 140 странами мира, почти тремя четвертями развивающихся стран и почти всеми странами с переходной экономикой. В последние годы их число быстро росло, и еще как минимум 500 находятся на стадии разработки. Большинство ОЭЗ - это зоны с несколькими видами деятельности. Специализированные в промышленности зоны и зоны с упором на инновации сосредоточены на наиболее развитых рынках развивающихся стран. Большинство ОЭЗ развитых стран ориентированы, прежде всего, на логистику. Использование зон странами на разных этапах индустриализации демонстрирует четкую схему развития ОЭЗ [5].

Экономические и политические цели, преследуемые при создании ОЭЗ в разных странах, существенно отличаются и зависят от уровня их развития. В развитых странах большинство ОЭЗ являются зонами, свободными от таможенных пошлин. Их роль заключается в освобождении от уплаты тарифов или в предоставлении льгот по их уплате и, что более важно, в освобождении от административного бремени таможенных процедур для оказания поддержки сложным трансграничным цепочкам поставок. В развивающихся странах, напротив, основная цель ОЭЗ, как правило, заключается в создании, диверсификации и модернизации отраслей за счет привлечения прямых иностранных инвестиций (ПИИ). Как показывает практика, страны, которые традиционно борются за привлечение ПИИ, демонстрируют более высокую склонность к принятию программ ОЭЗ [6]. Исключением являются малые островные развивающиеся государства, где доступность ресурсов для создания зон ограничена. ОЭЗ расположены и в большинстве стран с низким уровнем экономического развития (LDCs), а также в развивающихся странах, не имеющих выхода к морю (LLDCs) (таблица 1). Практически все страны с переходной экономикой имеют ОЭЗ, которые, как и в Китае, считаются полезными для построения рыночной экономики и расширения участия в международной торговле.

Несмотря на то, что ОЭЗ широко используются в мире, большая их часть сконцентрирована в нескольких странах. Только в Китае находится более половины всех мировых ОЭЗ. Среди других стран с большим количеством ОЭЗ выделяются Индия, США и Филиппины. Зональная концентрация наблюдается и на региональном уровне. Экономическая активность среди ОЭЗ также относительно сконцентрирована: несколько крупных зон 
Таблица 1.

Классификация стран мира в соответствии с уровнем развития экономики, имеющие

на своей территории зоны, действующие в соответствии с режимом ОЭЗ (данные по состоянию на 2019 г.)

\begin{tabular}{|c|c|c|c|c|}
\hline & Только $0 Э 3$ & $\begin{array}{c}0 Э 3 \text { и «свободные } \\
\text { точки» }\end{array}$ & $\begin{array}{c}\text { Только «свободные } \\
\text { точки» }\end{array}$ & $\begin{array}{l}\text { Нет 0Э3 / Нет } \\
\text { информации }\end{array}$ \\
\hline Всего в мире & 129 & 17 & 1 & 51 \\
\hline Развитые экономики & 26 & 0 & 0 & 12 \\
\hline Европа & 23 & 0 & 0 & 12 \\
\hline Северная Америка & 1 & 0 & 0 & 1 \\
\hline Развивающиеся экономики & 87 & 16 & 1 & 38 \\
\hline Африка & 32 & 5 & 1 & 16 \\
\hline Азия & 33 & 2 & 0 & 5 \\
\hline Восточная Азия & 4 & 1 & 0 & 2 \\
\hline Юго-Восточная Азия & 11 & 0 & 0 & 0 \\
\hline Южная Азия & 6 & 0 & 0 & 3 \\
\hline Западная Азия & 12 & 1 & 0 & 0 \\
\hline Латинская Америка и Страны Карибского бассейна & 20 & 9 & 0 & 7 \\
\hline Страны спереходной экономикой & 16 & 1 & 0 & 1 \\
\hline страны с низким уровнем экономического развития (LDCs) & 26 & 3 & 1 & 17 \\
\hline развивающиеся страны, не имеющие выхода к морю (LLDCs) & 20 & 2 & 1 & 9 \\
\hline малые островные развивающиеся государства (SIDS) & 6 & 4 & 0 & 18 \\
\hline
\end{tabular}

Источник: ЮНКТАД

привлекают значительные объемы инвестиций и обеспечивают крупную долю экспорта, в то время как многие другие, зачастую более мелкие зоны, остаются относительно неактивными. Тем не менее, даже одна или две зоны могут существенно повлиять на ПИИ страны и показатели экспорта [7].

В трех группах стран, объединенных в соответствии с особенностями экономического развития, наблюдается относительно низкая плотность ОЭЗ. В большинстве развитых стран нет ОЭЗ, кроме программ свободных зон. Деловая среда в них считается достаточно привлекательной, и многие предлагают альтернативные схемы поддержки для содействия торговле в трансграничных цепочках поставок, такие как льготный режим уплаты пошлин или системы таможенных складов. Во-вторых, страны, сталкивающиеся с конкретными географическими проблемами, в частности, как отмечалось выше, малые островные развивающиеся государства (SIDS) имеют ограниченные ресурсы для создания зон, а их расположение часто делает развитие ориентированного на экспорт производства менее жизнеспособным [8]. В-третьих, в странах с недостаточными ресурсами или относительно слабыми институциональными или управленческими возможностями также, как правило, расположено меньше ОЭЗ. Увеличение числа зон, создаваемых для привлечения внешних прямых иностранных инвестиций или получающих целевую государственную поддержку, в какой-то мере ослабили эти ограничения.

Развитие ОЭЗ происходило в регионах мира волнообразно. В каждом регионе большинство стран приняли территориальные программы развития в течение короткого периода времени. Большинство стран Восточной и Юго-Восточной Азии начали создавать ОЭЗ в 1970-х и начале 1980-х годов. В Латинской Америке большинство программ ОЭЗ были введены в конце 1980-х и 1990-х годов. Страны с переходной экономикой приняли режимы ОЭЗ в основном в 1990-х годах. В Африке большинство программ были приняты в 1990-х и 2000-х годах [9].

Волнообразное принятие программ ОЭЗ было обусловлено имплементацией лучших мировых практик развития свободных экономических зон и носило конкурентный характер. Успешная реализация программ ОЭЗ в Восточной и Юго-Восточной Азии, которые были частью экспортных стратегий развития, послужили примером для других регионов. Внутри регионов отдельные страны следовали примеру успешных программ, как только они становились доступными, и начинали конкурировать с ними. Поскольку территории конкурируют за инвестиции, ОЭЗ могут рассматриваться как инструмент для привлечения ПИИ, а также инструмент для ограничения «гонки уступок» в определенных районах. Изме- 
нения в политическом климате также способствовали волнообразному принятию программ ОЭЗ, особенно в странах, где ранее была плановая экономика. Именно там они способствовали экономическим экспериментам и относительно быстрым реформам бизнеса.

В результате развития ОЭЗ в разных условиях и в разное время сложившееся распределение зон по регионам и по типам существенно отличается. Большинство зон являются мультиактивными зонами (зонами с разными видами деятельности). Специализирующиеся на промышленности зоны чаще встречаются в странах с переходной экономикой. Инновационные зоны распространены на наиболее развитых из развивающихся рынков Азии. Большая часть зон на развитых рынках это чисто зоны свободной торговли, ориентированные на содействие торговой логистике [10].

Сравнительный анализ мирового опыта создания территорий с особым правовым статусом позволяет выявить определенную тенденцию: страны, как правило, принимают конкретные типы ОЭЗ в зависимости от стадии их экономического развития (таблица 2). Относительные новички в программах ОЭ3, такие как многочис- ленные страны Африки, используют ОЭЗ для стимулирования производства, индустриализации и экспорта [11]. Многие страны с более развитой экономикой используют зоны для стимулирования модернизации промышленности. В странах с переходной экономикой важны зоны, ориентированные на развитие технологий.

Эволюция развития ОЭЗ также проявляется и внутри стран, особенно среди тех, кто в числе первых начал внедрять программы ОЭЗ. Например, в азиатских странах с высоким уровнем дохода (в Республике Корея, Объединенных Арабских Эмиратах) зоны, которые первоначально предназначались для привлечения ориентированного на экспорт производства, теперь трансформируются в сторону услуг и вертикальной интеграции, тогда как в Латинской Америке и Карибском бассейне, СЭЗ, которые первоначально были сосредоточены только на складировании и логистике, развивались в направлении производства и услуг.

Таким образом, многие страны развивают более одного типа зон. Например, зоны свободной торговли (ЗСТ) и СЭЗ в Бразилии, а также ОЭЗ, «свободные точки» для одного предприятия и ЗСТ в Мексике. Это часто яв-

Таблица 2.

Сравнительный анализ мирового опыта создания территорий с особым правовым статусом

\begin{tabular}{|c|c|c|}
\hline $\begin{array}{l}\text { Распределение стран по уровню } \\
\text { национальногодохода }\end{array}$ & Цели зональной политики & Преобладающие типы зон \\
\hline $\begin{array}{l}\text { Страны с высоким уровнем на- } \\
\text { ционального дохода }\end{array}$ & $\begin{array}{l}\text { - Обеспечить эффективную платформу для сложных } \\
\text { трансграничных цепочек поставок } \\
\text { - Сосредоточиться на предотвращении перекосов в } \\
\text { экономике }\end{array}$ & $\begin{array}{l}\text { - Только свободные зоны логистических узлов (не про- } \\
\text { мышленные зоны) } \\
\text { • Инновации и новые цели промышленной революции, } \\
\text { преследуемые в научных парках без отдельной норма- } \\
\text { тивной базы или стимулов, не связанных с зонами }\end{array}$ \\
\hline $\begin{array}{l}\text { Страны с национальным доходом } \\
\text { выше среднего }\end{array}$ & $\begin{array}{l}\text { - Поддержка перехода к экономике услуг } \\
\text { • Привлечение новых высокотехнологичных отраслей } \\
\text { - Сосредоточение внимания на совершенствовании } \\
\text { инновационных возможностей }\end{array}$ & $\begin{array}{l}\text { - Технологические зоны (например, научно-исследова- } \\
\text { тельские, высокотехнологичные, биотехнологические) } \\
\text { - Специализированные зоны, предназначенные для } \\
\text { отраслей с высокой добавленной стоимостью или } \\
\text { сегментов производственно-сбытовой цепи } \\
\text { • Зоны обслуживания (например, финансовые услуги) }\end{array}$ \\
\hline $\begin{array}{l}\text { Страны со средним уровнем на- } \\
\text { ционального дохода }\end{array}$ & $\begin{array}{l}\text { - Поддержка модернизации промышленности } \\
\text { • Содействие интеграции и модернизации глобальной } \\
\text { цепочки создания добавленной стоимости } \\
\text { • Сосредоточение внимания на распространении техно- } \\
\text { логий }\end{array}$ & $\begin{array}{l}\text { - Специализированные зоны, ориентированные на } \\
\text { отрасли с интенсивным развитием глобальных цепочек } \\
\text { создания добавленной стоимости (например, автомо- } \\
\text { бильная промышленность, электроника) } \\
\text { • Зоны обслуживания (например, аутсорсинг бизнес-про- } \\
\text { цессов, центры обработки вызовов) }\end{array}$ \\
\hline $\begin{array}{l}\text { Страны с низким уровнем нацио- } \\
\text { нального дохода }\end{array}$ & $\begin{array}{l}\text { • Стимулирование промышленного развития и диверси- } \\
\text { фикации } \\
\text { • Улучшение инвестиционного климата } \\
\text { - Проведение бизнес-реформ в определенных отраслях } \\
\text { - Сосредоточение инвестиций в инфраструктуру в опре- } \\
\text { деленных отраслях }\end{array}$ & $\begin{array}{l}\text { • Многофункциональные зоны (мультиактивные) } \\
\text { • Ресурсные зоны, направленные на развитие перераба- } \\
\text { тывающих отраслей }\end{array}$ \\
\hline
\end{tabular}

Источник: ЮНКТАД 


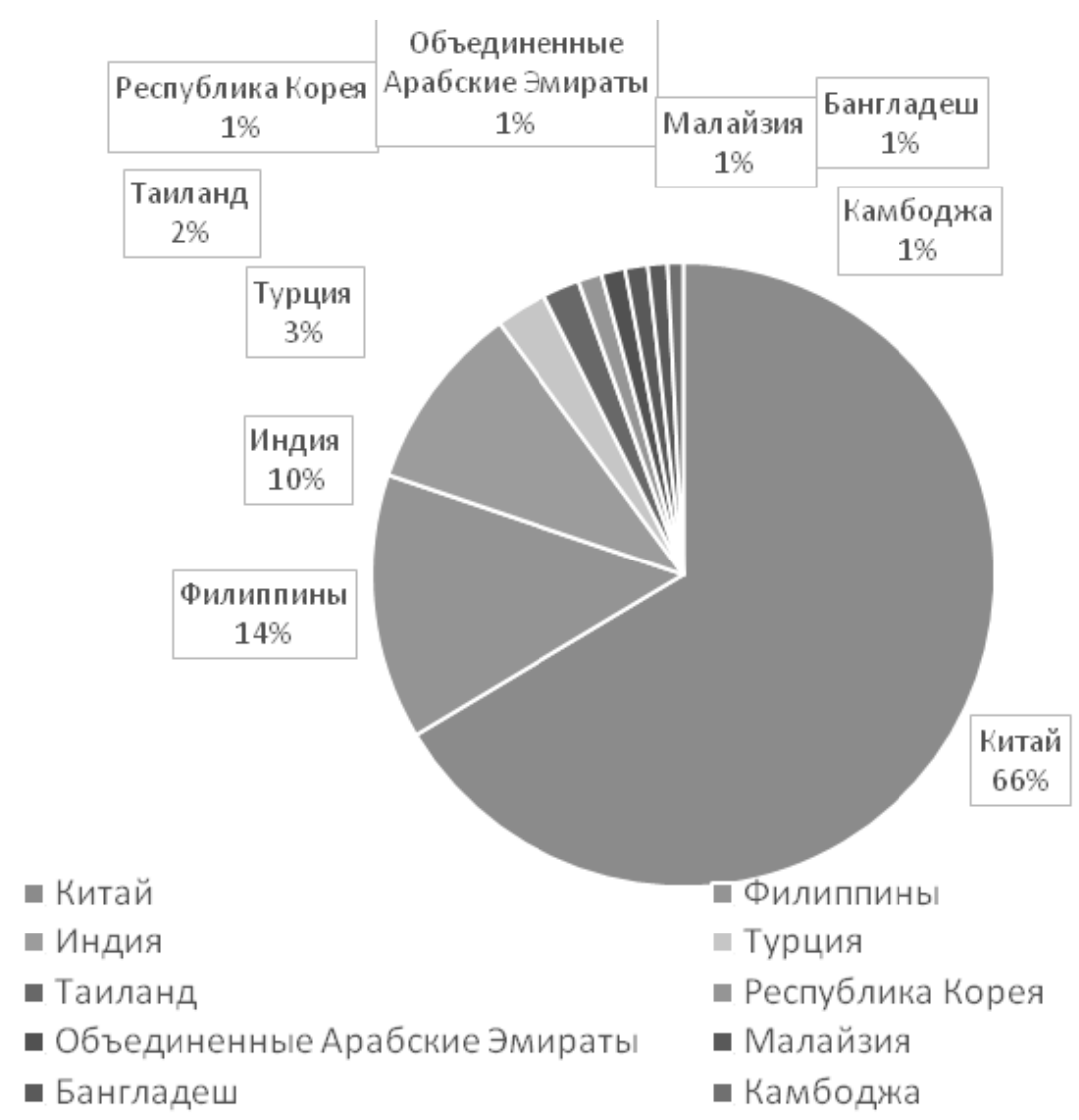

Рис. 1. Страны Азии с наибольшим количеством ОЭЗ, в процентах (данные по состоянию на 2019 г.)

ляется результатом перехода на новые модели ОЭЗ.

\section{Мировые практики созАания и развития ОЭЗ}

ОЭЗ широко используются в большинстве стран мира. Наибольшее количество ОЭЗ находится в Китае, на Филиппинах, в Индии, США, Российской Федерации, Турции, Таиланде, Доминиканской Республике, Кении и Никарагуа. Подход стран к развитию зон отличается в зависимости от: количества и физических размеров зон; концентрации зон на определенной территории или в рамках создания комбинированных схем взаимодействия; уровня специализации зон; проектирования зон в качестве отдельных промышленных площадок или интегрированных районов. Существует множество примеров амбициозных схем развития зон, стратегических программ по переориентации неэффективных зон и поэтапного отказа от зон [12].

\section{Опыт созАания особых экономических зон в странах Азии}

В Азии находится три четверти всех ОЭЗ мира. В процентном соотношении картина выглядит следующим образом (рисунок 1). В 35 странах региона действуют программы ОЭЗ. Характер и история развития ОЭЗ отли- чаются в зависимости от страны.

В странах Азии программы ОЭ3, начатые в 1970-е годы, также были недавно обновлены. С 2000-х годов в этих странах были введены различные типы зон, такие как специализированные ОЭЗ, ориентированные на услуги, и ОЭЗ, ориентированные на инновации. Это было сделано для диверсификации и модернизации базовых отраслей экономики [13]. Несколько богатых природными ресурсами азиатских стран, таких как Индонезия и Исламская Республика Иран, экспериментируют с ОЭЗ, которые специализируются на переработке природных ресурсов, для привлечения инвестиций в перерабатывающую отрасль.

Азиатские иностранные инвесторы (например, из Китая, Индии, Японии, Малайзии и Таиланда) участвуют в разработке и эксплуатации зон, привлекающих ПИИ в регион. Некоторые из них разрабатываются в сочетании с двусторонней и многосторонней финансовой помощью, и наращиванием потенциала (например, в Бангладеш и Мьянме).

В числе первых стран, создавших СЭ3, были китайская провинция Тайвань (1966 г.), Сингапур (1969 г.) и 
Республика Корея (1970 г.). Благодаря своим СЭЗ эти страны добились успеха в развитии трудоемких, ориентированных на экспорт отраслей, что послужило примером. Большинство других стран Юго-Восточной Азии приняли политику ОЭЗ в 1970-х годах [14].

Азиатские экономические кризисы в конце 1990-х годов заставили правительства сосредоточиться на повышении производительности и модернизации промышленности, чтобы снизить зависимость от дешевой рабочей силы. В результате СЭЗ переместились из зон с несколькими видами деятельности в специализированные, а в более развитых странах - в СЭЗ, основанные на инновациях. Например, китайская провинция Тайвань создала три научных парка в 1980-х годах и четыре экологических научно-технических парка в 2000-х годах. В 2000-х годах в рамках стратегии модернизации промышленности были также созданы три специализированные ОЭ3, занимающиеся биотехнологиями в сфере сельского хозяйства. Гаосюн - первая СЭЗ в китайской провинции Тайвань, в рамках которой были созданы специальные области для индустрии программного обеспечения и логистики [15].

Местные зоны были введены для ускорения экономического роста в слаборазвитых регионах. Например, в Республике Корея в начале 2000-х годов были созданы свободные экономические зоны для стимулирования ПИИ и сбалансирования регионального роста. В рамках таких зон создаются не только производственные объекты, но и жилые районы, организуется предоставление качественных медицинских и образовательных услуг, возможностей для отдыха. В стране восемь таких зон, а также 13 ЗСТ и 26 специализированных ОЭЗ (специальные зоны внешней торговли).

Подобные преобразования политики ОЭЗ произошли и в Юго-Восточной Азии. Сингапур создал многоотраслевые зоны в 1960-х годах и специализированные ОЭ3 (например, нефтеперерабатывающие заводы) в 1970-х годах. В 2000-х годах политика СЭЗ сместилась в сторону создания наукоемких кластеров за счет создания инновационных ОЭЗ, ориентированных на НИОКР и другие виды деятельности с высокой добавленной стоимостью. На Филиппинах ОЭЗ эволюционировали, превратившись из беспошлинных зон, ограниченных внешней торговлей, впервые введенных в 1969 году, в мульти зоны - зоны с множеством видов деятельности (ОЭЗ, в которых размещается только производство) в 1970-х годах, а затем в специализированные ОЭЗ в 1990-х годах - «экозоны», в которых размещаются два вида деятельности, как производство, так и сервисные услуги, вклю- чая информационно-коммуникационные технологии и аутсорсинг бизнес-процессов.

Сегодня ОЭЗ стран азиатского региона имеют, преимущественно, отраслевую направленность - производство, информационные технологии (ИТ), агропромышленный комплекс, туризм или здравоохранение. Страны CLMV (Камбоджа, Лаосская Народно-Демократическая Республика, Мьянма и Вьетнам)² начали создавать ОЭЗ для привлечения трудоемкого производства в конце 1990-х и 2000-х годов. Камбоджа запустила новую программу ОЭЗ в 2005 году, создав специализированные ОЭЗ для диверсификации своей промышленной базы. Другие страны региона с низким уровнем национального дохода только начинают свои программы ОЭЗ. Мьянма имеет одну ОЭЗ, еще две строятся в сотрудничестве с Китаем, Японией и Таиландом [16].

Помимо влияния на национальную экономику, ОЭЗ в Восточной и Юго-Восточной Азии также вносят значительный вклад в региональную экономическую интеграцию, содействуя развитию региональных производственно-сбытовых цепочек. Ряд недавно созданных ОЭЗ в регионе предназначен для содействия не только региональной торговле, но и обмену ресурсами. В Камбодже, Лаосской Народно-Демократической Республике и Таиланде большинство ОЭЗ были созданы вблизи пограничных коридоров с соседними странами для содействия трансграничной торговле и инвестициям.

Кроме того, некоторые ОЭЗ в Юго-Восточной Азии явно стремятся решать проблемы неравномерного развития внутри стран. Одной из целей СЭЗ в Камбодже является установление экономических связей между городскими и сельскими районами. В Малайзии в 2000-х годах были созданы региональные экономические коридоры - новый тип ОЭЗ - для содействия развитию сельских провинций.

Исходя из результатов проведенного исследования можно сделать вывод, что для успешного функционирования ОЭЗ нельзя обойтись без привлекательных условий для инвесторов. В связи с чем ОЭЗ пользуются обширными налоговыми льготами, которые используются с целью привлечения инвестиций и в конечном итоге стимулирования роста показателей экономики, в том числе наращивание темпов экспорта.

Опыт функционирования территорий с особым правовым статусом по всему миру показывает, какое положительное влияние они могут оказать на национальную

2 CLMV countries (Cambodia, the Lao People's Democratic Republic, Myanmar and Viet Nam) 
экономику государства, в том числе рост и диверсификацию экспорта, улучшение показателей занятости населения, приток прямых иностранных инвестиций. Несмотря на то, что ОЭЗ присутствуют в большинстве экономик мира, наибольшую эффективность они проявляют в развивающихся странах, нуждающихся в иностранных инвестициях, в то время как развитые страны используют ОЭЗ для таких целей как стимулирование создания высокотехнологичных производств и перетока капитала из реального в финансовый сектор. Опыт экономически развивающихся стан Азии следует признать по большей части положительным и рекомендовать некоторые инструменты, касающиеся развития инновационо-технологического комплекса, интегрировать в существующие ОЭЗ в Российской Федерации в целях увеличения эффективности их функционирования и достижения национальных целей развития Российской Федерации на период до 2030 года.

ЛИТЕРАТУРА

1. Меджидов 3.У. Зарубежный опыт функционирования особых экономических зон // Вектор науки тольяттинского государственного университета. Серия: экономика и управление. 2016. №1. С. 55-61.

2. Смородинская Н.В. Организация особых экономических зон в мировой и российской практике: концептуальные аспекты // Вестник Института экономики Российской академии наук. 2011. № 3. С. 16-36.

3. Улицкая Н.Ю., Акимова М.С., Кокорева Т.П. Территория опережающего социально-экономического развития как фактор развития территории и привлекательности для резидента // Стратегии бизнеса. 2017. № 10 (42). С. 12-16.

4. Баландина А.С., Баннова К.А., Брайченко А.А. Зарубежный опыт создания особых экономических зон в развитых странах // Проблемы учета и финансов. 2016. № 4 (24). С. 60-63.

5. Фаттахов Р.В., Строев П.В. Пространственный аспект модернизации экономики России // Экономика. Налоги. Право. 2015. № 6. С. 6-14.

6. Вертакова Ю.В., Положенцева Ю.С., Клевцова М.Г. Санкции в условиях глобализации и их влияние на экономическое развитие России // Экономика и управление. 2015. № 10. С. 24-32.

7. Гибадуллин А.А. Концептуальные направления развития промышленности Евразийского экономического союза // Вестник СибАДИ. 2017. №4-5 (56-57) C. 152-159.

8. Морковкин Д.Е., Строев П.В., Макар С.В. Динамика трансграничных потоков капитала стран ЕАЭС: пространственный анализ // Финансовая жизнь. 2019. № 1. С. 34-37.

9. Промышленная политика в эпоху цифровой трансформации экономики: монография / В.П. Бауэр, Д.Е. Морковкин, Е.И. Москвитина, 0.И. Маликова, С.Н. Сильвестров, А.Ю. Тепляков, С.А. Толкачев, Т.М. Цветкова / под ред. С.А. Толкачева. - М.: КНОРУС, 2018. - 204 с.

10. Морковкин Д.Е. Современные инструменты пространственного регулирования ускоренного социально-экономического развития России // Муниципальная академия. 2017. № 2. С. 25-36.

11. Низамутдинов М.М., Орешников В.В. Подход к разработке инструментария информационной поддержки инновационного развития региона // Инновационные технологии управления социально-экономическим развитием регионов России. Институт социально-экономических исследований Унц РАН. $-2019 .-$ C.141-147.

12. Фаттахов Р.В., Лапенкова Н.В., Пивоварова О.В. Территории с особым правовым статусом как инструмент инновационно-инвестиционного развития: мировая практика // Экономика. Бизнес. Банки. 2019. № 11 (37). С. $21-33$.

13. Пивоварова 0.В. Международный опыт оценки эффективности государственного управления // Государственное и муниципальное управление. Ученые записки. - 2020. - № 2. - С. 80-86.

14. Эскиндаров М.А., Масленников В.В., Солянникова С.П., Морковкин Д.Е., и др. Стратегия ЦСР 2018-2024 гг.: лозунги, мифы и реальность (позиция экспертов финансового университета)// Вестник Финансового университета. 2017. Т. 21. № 3 (99). С. 6-24.

15. Morkovkin D., Shmanev S., Shmaneva L. Problems and Trends in Innovative Transformation of Russian Economy and Infrastructure Development // Proceedings of the 3rd International Conference on Economics, Management, Law and Education (EMLE 2017). - 2017. - T. 32. - C. 10-13.

16. Global Experiences with Special Economic Zones [Электрон. ресурс]. Режим доступа: Open knowledge. URL: https://openknowledge.worldbank.org/bitstream/ handle/10986/22400/Global0experie00onOChina0andOAfrica.pdf?sequence=1 (дата обращения: 20.09.2020)

\footnotetext{
(с Строев Павел Викторович (stroevpavel@gmail.com), Макар Светлана Владимировна (swetwn@mail.ru), Дудник Анна Игоревна (AlDudnik@fa.ru)

Журнал «Современная наука: актуальные проблемы теории и практики»
} 